\title{
Monodispersed Spindle-like Particles of Titania
}

\author{
Nataliya Murafa*, Václav Stengl ${ }^{*}$, Vendula Houšková ${ }^{*}$ \\ *Institute of Inorganic Chemistry of the ASCR, v. v. i., 25068 Řež, Czech Republic
}

$\mathrm{TiO}_{2}$ is a semiconductor with a well-known photocatalytic activity [1]. $\mathrm{TiO}_{2}$ is a polymorphous compound, crystallizing as rutile, anatase, or brookite. The first two polymorphs are the most intensively studied, whereas brookite properties are less known due to complications with its preparation in a pure microcrystalline form. Anatase is usually more active, but the actual efficiency of titanium dioxide depends not only on its phase composition, but also on the particle size, morphology, and porosity. Anatase higher activity is usually attributed to its larger specific surface area. Hence, the detailed phase and morphological analysis of each particular catalyst is required to optimize its properties.

We prepared nanocrystalline monodispersive anatase particles by ageing of peroxotitanate acid. $1 \mathrm{M}$ solution of titanium oxo-sulphate was neutralized by stoicheiometric amount of $25 \%$ solution of ammonium hydroxide at temperature of $0{ }^{\circ} \mathrm{C}$. Precipitated $\mathrm{Ti}(\mathrm{OH})_{3} \cdot \mathrm{nH}_{2} \mathrm{O}$ gel was five times decanted with distilled water and filtered off. Obtained wet gel was mixed with $30 \%$ hydrogen peroxide solution. The yellow see-through gelatin product was obtained by foregoing reaction and subsequently annealed in electrical heating nest in a round-bottom flask with a reflux cooler. During the heating process yellow-white precipitate was originated. Annealing had been continued till the precipitate changed its color to absolutely white ( $\sim 8$ hours). The obtained white precipitate was dried in the oven at $5^{\circ} \mathrm{C}$. The obtained product had been heated at the temperature range of 100-800 ${ }^{\circ} \mathrm{C}$.

The prepared samples obtained by the ageing process were characterized by several instrumental techniques (XRD, HRTEM, SEM/EDAX). The results of measurements show that primary titania particles have uniform spindle-like morphology [2]. The SAED confirmed anatase phase. The photocatalyic activity was evaluated by the kinetics of Orange 2 dye degradation and compared to the material commercially available (Degussa P25). Photocatalytic properties of the anatase sample were higher than the commercially available specimen P25.

References:

[1] M.V. Shankar et al., Journal of Colloid and Interface Science 331 (2009) 132-137

[2] J.A.Chang et al., Journal of Solid State Chemistry, In Press, 2009

[3] This work was supported by the Czech Science Foundation (project № 203/08/0335) and by the Academy of Sciences of the Czech Republic (Project № AVOZ40320502) 

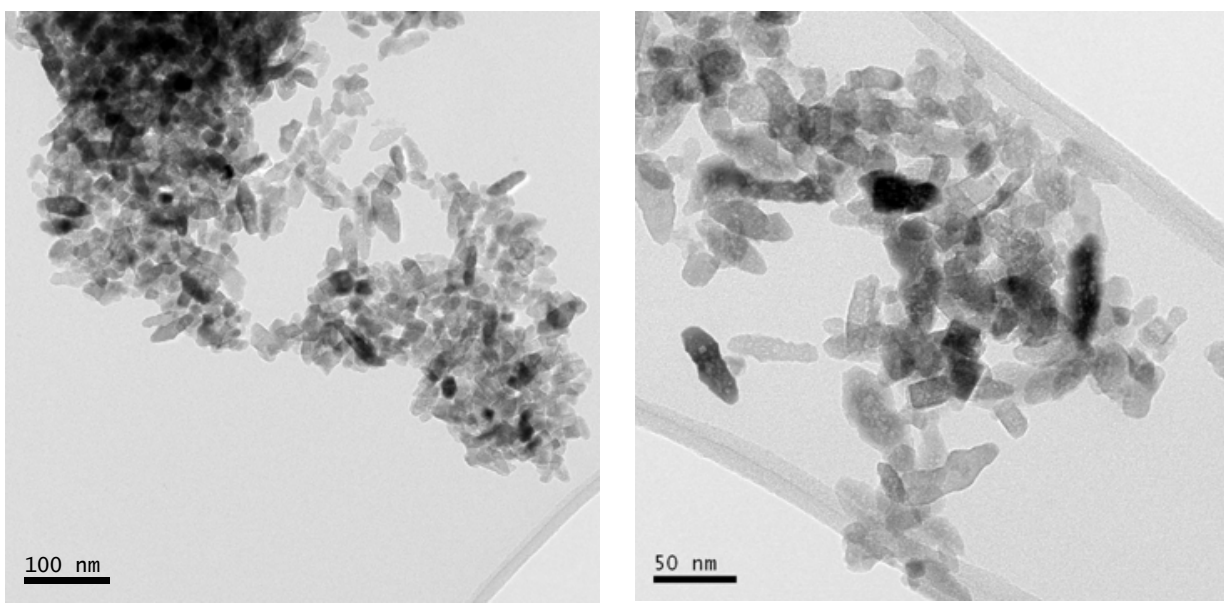

Fig. 1. TEM micrographs of a spindle-like particle of titania
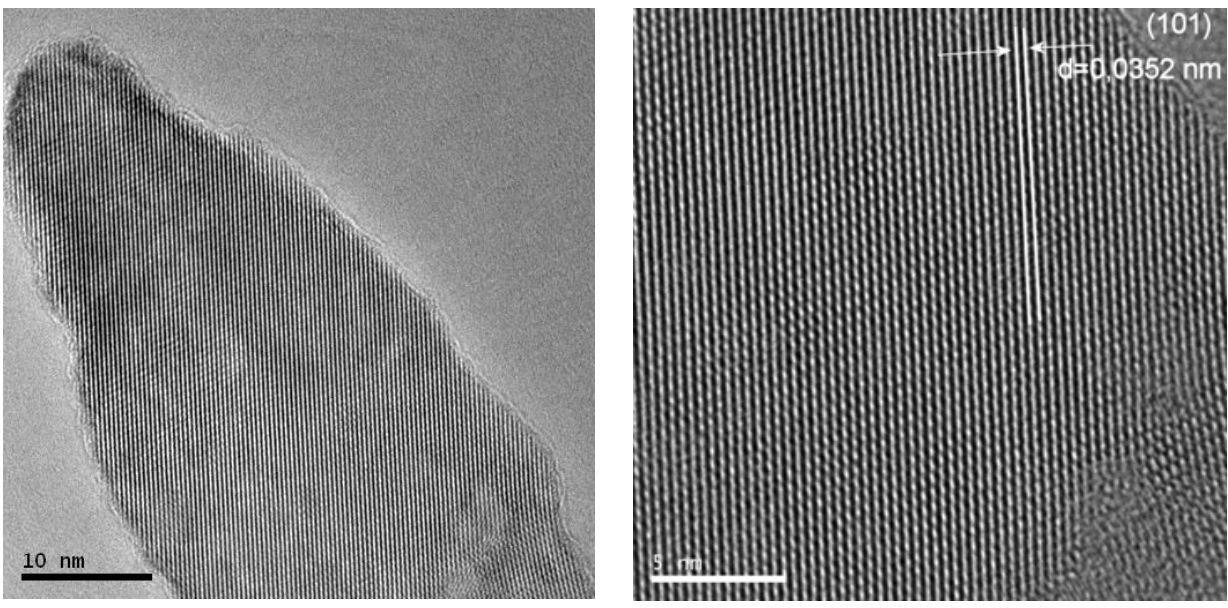

Fig. 2. HRTEM micrographs of the anatase phase
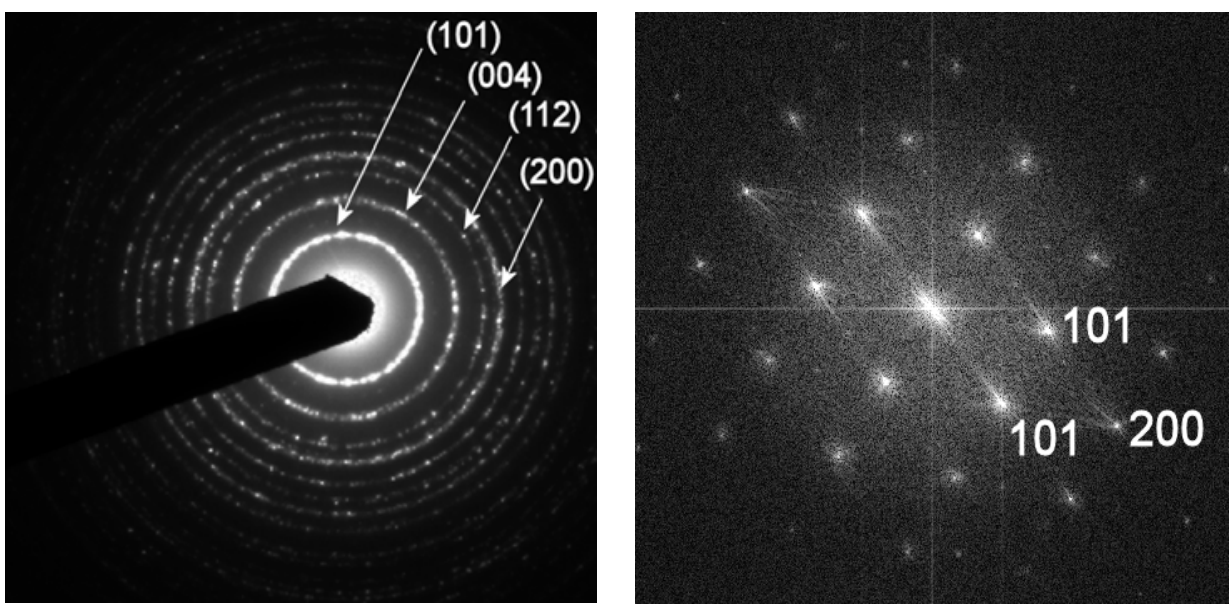

Fig. 3. Electron diffraction patterns of the obtained sample 